\title{
Sequential Combination of Cognitive-Behavioral Treatment and Well-Being Therapy in Depressed Patients with Acute Coronary Syndromes: A Randomized Controlled Trial (TREATED-ACS Study)
}

\author{
Chiara Rafanelli $^{a} \quad$ Sara Gostoli $^{a} \quad$ Sara Buzzichellib Jenny Guidi ${ }^{\mathrm{a}} \quad$ Laura Sirri $^{\mathrm{a}}$ \\ Pamela Gallo $^{c}$ Enrica Marzolab Serena Bergerone ${ }^{d}$ Gaetano Maria De Ferrari ${ }^{d}$ \\ Renzo Roncuzzi $^{\mathrm{e}}$ Giuseppe Di Pasquale ${ }^{c}$ Giovanni Abbate-Dagab \\ Giovanni A. Fava ${ }^{f}$

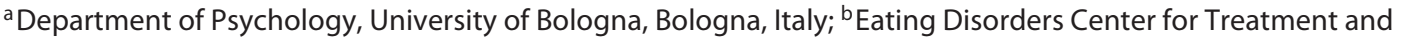 \\ Research, Department of Neuroscience, University of Turin, Turin, Italy; ${ }^{C}$ Division of Cardiology, Maggiore Hospital, \\ Bologna, Italy; ${ }^{d}$ Division of Cardiology, Internal Medicine Department, Città della Salute e della Scienza, \\ University of Turin, Turin, Italy; ${ }^{e}$ Division of Cardiology, Bellaria Hospital, Bologna, Italy; ${ }^{f}$ Department of Psychiatry, \\ University at Buffalo, Buffalo, NY, USA
}

\section{Keywords}

Acute coronary syndrome · Cognitive-behavioral therapy · Depression · Sequential treatment · Well-being therapy

\begin{abstract}
Introduction: Randomized controlled trials (RCT) of psychotherapeutic interventions have addressed depression and demoralization associated with acute coronary syndromes (ACS). The present trial introduces psychological well-being, an increasingly recognized factor in cardiovascular health, as a therapeutic target. Objective: This study was designed to determine whether the sequential combination of cognitive-behavioral therapy (CBT) and well-being therapy (WBT) may yield more favorable outcomes than an active control group (clinical management; CM) and to identify subgroups of patients at greater risk for cardiac negative outcomes.
\end{abstract}

karger@karger.com

(C) 2020 S. Karger AG, Basel

www.karger.com/pps

Karger
Methods: This multicenter RCT compared CBT/WBT sequential combination versus $C M$, with up to 30 months of followup. One hundred consecutive depressed and/or demoralized patients (out of 740 initially screened by cardiologists after a first episode of ACS) were randomized to CBT/WBT associated with lifestyle suggestions $(n=50)$ and CM $(n=50)$. The main outcome measures included: severity of depressive symptoms according to the Clinical Interview for Depression, changes in subclinical psychological distress, wellbeing, and biomarkers, and medical complications and events. Results: CBT/WBT sequential combination was associated with a significant improvement in depressive symptoms compared to CM. In both groups, the benefits persisted at follow-up, even though the differences faded. Treatment was also related to a significant amelioration of biomarkers (platelet count, HDL, and D-dimer), whereas the 2 groups showed similar frequencies of adverse cardiac events. Con- 
clusions: Addressing psychological well-being in the psychotherapeutic approach to ACS patients with depressive symptoms was found to entail important clinical benefits. It is argued that lifestyle changes geared toward cardiovascular health may be facilitated by a personalized approach that targets well-being.

(c) 2020 S. Karger AG, Basel

\section{Introduction}

There is extensive evidence that the presence of depressive symptoms in acute coronary syndromes (ACS) is associated with poor therapeutic adherence, a higher frequency of relapses, and increased mortality [1]. Mood disturbances may consist of major or minor depressive episodes, chronic depression, and demoralization [1-3], which is characterized by a sense of subjective incompetence [4].

The relationship of depression to ACS has generated the hypothesis that treatment of mood disturbances may yield improved medical and psychological outcomes. A number of randomized controlled trials (RCT) have indicated the effectiveness of antidepressant drugs compared to placebo in relieving depression, yet a favorable effect on cardiovascular events was not detected [1] or could not be generalized [5]. Similar findings have been reported for the application of cognitive-behavioral therapy (CBT) to ACS [6], pioneered by the ENRICHD trial [7].

Psychotherapeutic approaches, however, have been mainly shifted to the side of psychological dysfunction and have neglected psychological well-being. There is increasing evidence of the role of positive psychological assets on lifestyle and cardiovascular health [8].

In this trial, the sequential use of distress and well-being psychotherapeutic strategies was selected. The first phase of treatment (CBT) was concerned with distress associated with hospitalization and medical events. In the second phase, well-being therapy (WBT), a specific psychotherapeutic approach for modulating psychological well-being [9], was introduced and suggestions for lifestyle modifications geared to cardiovascular health were provided [10]. The sequential combination of CBT and WBT has been found to yield enduring clinical benefits in the setting of psychiatric disorders $[9,10]$, with particular reference to recurrent depression [11].

The aim of the trial was to evaluate the efficacy of the sequential combination of CBT and WBT, compared to clinical management (CM), in terms of depressive symptoms (primary outcome), psychological distress, and well-being, as well as cardiovascular events, biomarkers, and mortality (secondary outcomes), both after treatment and up to a 30-month follow-up. The identification of subgroups of patients at greater risk for cardiac negative outcomes was included.

\section{Materials and Methods}

\section{Sample}

Participants were patients hospitalized for a first episode of acute myocardial infarction or unstable angina at the Cardiology Divisions of Maggiore Hospital (Bologna, Italy) and Molinette Hospital (Torino, Italy). Myocardial infarction was documented based on cardiac symptoms (presence of acute chest, epigastric, neck, jaw, or arm pain or discomfort or pressure without an apparent noncardiac source) and signs (acute congestive heart failure or cardiogenic shock in the absence of non-CHD causes) associated with ECG findings (characteristic evolutionary ST-T changes or new $\mathrm{Q}$ waves) and/or cardiac biomarkers (blood measures of myocardial necrosis, specifically $\mathrm{CK}, \mathrm{CK}-\mathrm{MB}, \mathrm{CK}-\mathrm{MBm}$, or troponin, and $\mathrm{cTn}$ ). Instable angina was documented based on cardiac symptoms (chest pain lasting less than $20 \mathrm{~min}$ ) with likely ECG findings (ST-segment depression and an abnormal T-wave) in absence of myocardial necrosis biomarkers.

Medically eligible patients underwent a psychological evaluation by 2 clinical psychologists with expertise in the field of psychosomatic aspects of cardiovascular diseases about 30 days after ACS. The inclusion criteria were: a current diagnosis of major/ minor depression or dysthymia according to DSM-IV-TR [12] and/or demoralization according to Diagnostic Criteria for Psychosomatic Research (DCPR) criteria [13]. The exclusion criteria included a positive history of bipolar disorder (DSM-IV-TR), major depression with psychotic features, a positive history of substance abuse/dependence during the previous 12 months, suicide risk, and current use of antidepressants and/or psychotherapy.

A psychological evaluation was performed in 288 patients with a first episode of ACS, and the first 100 depressed and/or demoralized consecutive patients were enrolled (Fig. 1).

\section{Assessment}

Medical Variables

Data on ACS, traditional cardiac risk factors (smoking habit, hypertension, dyslipidemia, a family history of cardiovascular disease, diabetes mellitus, and left ventricular ejection fraction $<40$ ), medications, and comorbidities were collected from medical records. The cardiologists involved in this study evaluated the patients at intake and once every 6 months to monitor changes in the clinical course of cardiac disease. Data from electrocardiograms, echocardiograms, X-rays, blood pressure and blood samples (cholesterol levels, creatinine, glycosylated hemoglobin, C-reactive protein, and coagulation/fibrinolysis biomarkers) were provided at intake. The Global Registry of Acute Coronary Events (GRACE) risk index [14] was calculated during hospital admission for ACS to determine the risk of morbidity and mortality both in hospital and 6 months after discharge. From the beginning of the psychological treatment and up to a 30-month follow-up after the end of the intervention, information about cardiac negative outcomes, 


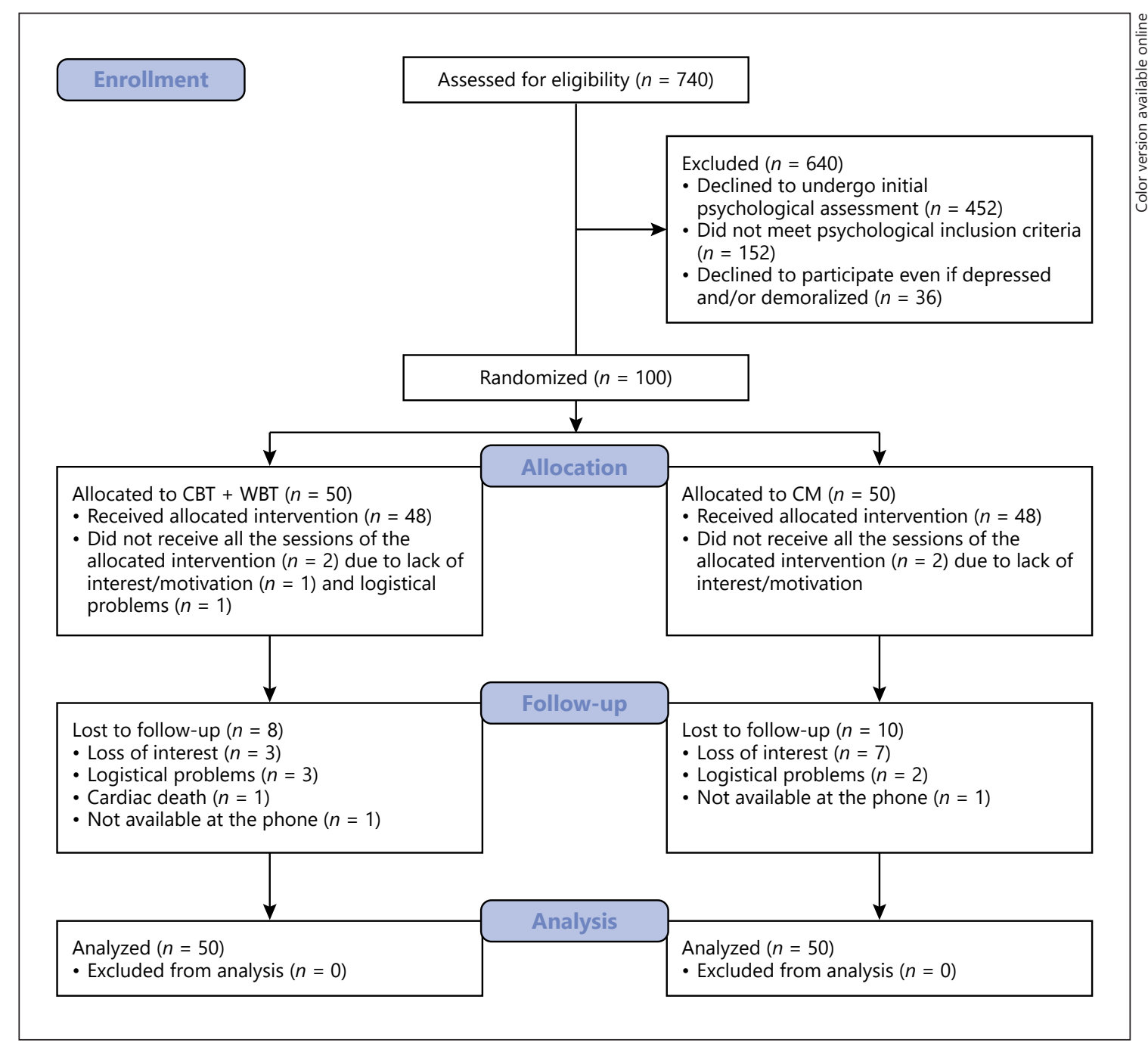

Fig. 1. CONSORT flow diagram of this study.

such as rehospitalizations due to cardiac complications, acute myocardial infarction, unstable angina, angioplasty, cardiac surgery, and cardiac mortality after the first ACS, was collected.

\section{Psychological Variables}

Psychological assessment included both observer-rated and self-reported measures before the beginning of the interventions (baseline, pretreatment), at the end (posttreatment), and 3, 6, 12, and 30 months after the end of treatment. The Structured Clinical Interview for DSM-IV-TR, Axis I Disorders [15], was used to investigate the presence of major/minor depression and dysthymia. The Semi-Structured Interview based on the DCPR (SSI-DCPR) [16] was administered to assess the presence of demoralization [17]. This interview has shown excellent interrater reliability, with $\kappa$ values ranging from 0.69 to 0.97 [18]. The 20 -item change version of the Clinical Interview for Depression (CID) [19, 20], a modified version of the Hamilton Rating Scale for Depression [21, 22], was used to perform a comprehensive assessment of affective symptoms. It contains 20 items rated on a 7-point Likert scale, with spec- ification of each anchor point based on the severity, frequency, and/ or quality of the symptoms. The higher the score, the worse the psychological condition. The CID has been shown to be a sensitive assessment tool in clinical trials [20]. The Symptom Questionnaire (SQ) $[23,24]$ is a 92 -item self-report questionnaire that yields 4 main scales, i.e., depression, anxiety, hostility-irritability, and somatization. The higher the score, the higher the psychological distress. The Psychological Well-Being scales (PWB) [25-26], an 84item questionnaire, was used to evaluate 6 psychological well-being dimensions (autonomy, environmental mastery, personal growth, positive relations, purpose in life, and self-acceptance). Higher scores correspond to greater psychological well-being.

\section{Study Design}

This study is a 2-center RCT with a longitudinal and prospective design. The enrolled patients were randomly assigned to either $\mathrm{CBT} / \mathrm{WBT}$ or CM and assessed at the beginning and the end of the CBT/WBT or CM sessions, and at subsequent follow-ups up to 30 months after the conclusion of the interventions. Treatment allo- 
cation was accomplished through random computerized assignment that allocated $50 \%$ of the patients to each treatment group, with assignments concealed until the time of group assignment. Patients were assessed by 2 clinical psychologists, who were blind to treatment assignment, at pretreatment and posttreatment, and $3,6,12$, and 30 months after the end of treatment. Both the sequential combination of CBT/WBT and the CM were performed by psychotherapists who had received specific training. Both interventions consisted of 12 weekly, 45-min sessions. The sequential administration of CBT (8 sessions) and WBT (4 sessions) was based on a written protocol [9-10]. The WBT techniques were used to improve or balance one or more of the 6 dimensions of psychological well-being (environmental mastery, purpose in life, personal growth, autonomy, self-acceptance, and positive relations with others), and they were supplemented with suggestions for lifestyle modifications geared toward cardiovascular health, including treatment adherence.

$\mathrm{CM}$ entails the same amount of time and attention from a professional figure than the experimental group, but specific interventions (such as exposure strategies, diary work, and cognitive restructuring) were proscribed [27]. Such a form of active control unlike in previous trials that have used treatment as usual [6] - allows discrimination of specific and nonspecific ingredients of the psychotherapeutic approach. It consists of empathic listening, review of the patient's clinical status and providing opportunities for disclosure of distress and worries, and encouragement of treatment adherence.

\section{Statistical Analyses}

Data were analyzed using SPSS 20.0 (SPSS Inc., Chicago, IL, USA). The quality of data collection was monitored regularly to assure accuracy and completeness. For all tests performed, significance level was set at 0.05 (two-tailed). The sample size was estimated using Piface software, which identified a minimum of 16 participants per arm to detect the expected superiority of CBT/ WBT on CM [11], with a power of $80 \%$ and a significance level of $5 \%$. Thus, with 50 patients per group we expected a "large" effect size (Cohen's $d=0.8$ ) [28].

A multivariate ANOVA was used to examine differences in dimensional psychological variables (i.e., CID-20 total score and PWB and SQ scale scores) between patients assigned to CBT/WBT and $\mathrm{CM}$ at preintervention.

A mixed-model ANOVA (repeated measures) was performed to test differences between groups (CBT/WBT or CM) on the CID20 total score, PWB scales, and SQ scales scores at different followup evaluations. All analyses were performed by using intention-totreat analysis, where missing values were managed by means of a multiple-imputations procedure. Greenhouse-Geisser correction was applied when appropriate. All analyses were adjusted for cardiac illness severity (i.e., GRACE index for the 6-month probability of cardiac mortality) [14].

Each biomarker was dichotomized around the baseline median of the sample in order to identify subgroups of patients at a higher cardiovascular risk. The McNemar test (applied to contingency tables) was used to identify significant changes over time in the frequencies of DSM, DCPR diagnoses, and subgroups of patients at a higher cardiovascular risk.

Survival analyses (Cox Regression and Kaplan-Meier) to identify cardiac events and mortality that occurred between pretreatment and the 30-month follow-up were performed.

\section{Results}

\section{Baseline Profile of the Sample}

The first 100 consecutive depressed and/or demoralized patients 1 month after ACS were enrolled, yielding 50 patients in each treatment group. The mean age of the sample was 58.8 years $(\mathrm{SD}=10.5$, range $40-84)$. The participants were mainly men (69\%), married (69\%), employed (58\%), and graduated from high school (44\%). No significant differences based on group allocation were found (Table 1).

As for the cardiac profile of the sample, ST-elevation myocardial infarction (STEMI) was the most frequent form of ACS (66\%) and almost all of the patients (94\%) underwent percutaneous transluminal coronary angioplasty $-77 \%$ with the application of a single stent and $17 \%$ with 2 or more stents. The most frequent cardiovascular risk factors registered at hospital admission were dyslipidemia (58\%) and hypertension (52\%). No differences concerning ACS-related aspects or GRACE risk scores were found when comparing CBT/WBT versus $\mathrm{CM}$ (Table 1).

Among the medications prescribed at discharge, the most frequent were statins (96\%), $\beta$-blockers (96\%), and platelet aggregation inhibitors (96\%). Patients allocated to $\mathrm{CM}$ were prescribed significantly more frequently $\beta$-blockers, calcium antagonists, and $\alpha$-adrenergic receptor inhibitors compared to the CBT/WBT group (Table 1). The sample presented with a number of medical comorbidities; the most frequent were gastrointestinal (43\%) and endocrine diseases (14\%). As for comorbid medical diagnoses and levels of biomarkers assessed at baseline, the 2 groups did not show any significant difference (Table 1). From the psychological point of view, the most frequent diagnosis was demoralization (91\%), followed by minor depression (56\%). The 2 groups did not show any statistical difference, except for PWB "personal growth" scores $(F=4.45$; $\mathrm{df}=1,98$; $p=0.038)$ and frequency of depression/demoralization comorbidity $\left(\chi^{2}=4.86 ; \mathrm{df}=1 ; p=0.028\right)$, which were significantly higher among the CBT/WBT patients (Table 1).

\section{Pre-/Postintervention Modifications}

Psychological Variables

Forty-eight patients completed the CBT/WBT treatment, and 48 patients attended CM sessions. Two patients in each group dropped out early, mainly due to a lack of interest or motivation. Forty and 38 patients, respectively, completed follow-up evaluations (Fig. 1). 
Table 1. Baseline sociodemographic, medical, and psychological profile of the sample

\begin{tabular}{|c|c|c|}
\hline Variable & $\begin{array}{l}\text { CBT/WBT group } \\
(n=50)\end{array}$ & $\begin{array}{l}\text { CM group } \\
(n=50)\end{array}$ \\
\hline Mean age (SD), years & $57.64(9.99)$ & $60.02(10.94)$ \\
\hline \multicolumn{3}{|l|}{ Sex, $n(\%)$} \\
\hline Males & $31(62)$ & $38(76)$ \\
\hline Females & $19(38)$ & $12(24)$ \\
\hline \multicolumn{3}{|l|}{ Marital status, $n(\%)$} \\
\hline Single & $4(8)$ & $7(14)$ \\
\hline Married & $33(66)$ & $36(72)$ \\
\hline Separated & $5(10)$ & $4(8)$ \\
\hline Divorced & $2(4)$ & $1(2)$ \\
\hline Widow/widower & $6(12)$ & $2(4)$ \\
\hline \multicolumn{3}{|l|}{ Occupation, $n(\%)$} \\
\hline Employed & $34(68)$ & $24(48)$ \\
\hline Unemployed & $1(2)$ & $4(8)$ \\
\hline Retired & $13(26)$ & $19(38)$ \\
\hline Homemaker & $2(4)$ & $3(6)$ \\
\hline \multicolumn{3}{|l|}{ Education, $n(\%)$} \\
\hline Primary school & $5(10)$ & $5(10)$ \\
\hline Middle school & $16(32)$ & $18(36)$ \\
\hline High school & $19(38)$ & $25(50)$ \\
\hline University & $8(16)$ & $1(2)$ \\
\hline Postgraduate education & $2(4)$ & $1(2)$ \\
\hline \multicolumn{3}{|l|}{ Type of ACS, $n(\%)$} \\
\hline STEMI acute myocardial infarction & $33(66)$ & $33(66)$ \\
\hline NSTEMI acute myocardial infarction & $14(28)$ & $13(26)$ \\
\hline Unstable angina & $3(6)$ & $4(8)$ \\
\hline \multicolumn{3}{|l|}{ Medical procedure for ACS, $n(\%)$} \\
\hline Single PTCA & $38(76)$ & $39(78)$ \\
\hline PTCA with 2 or more stents & $9(18)$ & $8(16)$ \\
\hline None & $3(6)$ & $3(6)$ \\
\hline Drug-eluting stent & $24(51.1)$ & $18(38.3)$ \\
\hline \multicolumn{3}{|l|}{ Cardiovascular risk factors, $n(\%)$} \\
\hline Dyslipidemia & $31(62)$ & $27(54)$ \\
\hline Hypertension & $27(54)$ & $25(50)$ \\
\hline Smoker (current) & $22(44)$ & $20(40)$ \\
\hline Familiarity & $17(34)$ & $11(22)$ \\
\hline Diabetes & $10(20)$ & $9(18)$ \\
\hline LVEF $<40$ & $4(8)$ & $3(6)$ \\
\hline \multicolumn{3}{|c|}{ Mean GRACE risk index at admission (mortality) (SD) } \\
\hline In-hospital risk, $\%$ & $3.51(8.58)$ & $4.56(7.90)$ \\
\hline 6-month risk, \% & $6.60(11.60)$ & $8.69(10.57)$ \\
\hline \multicolumn{3}{|c|}{ Mean GRACE risk index at admission (mortality + AMI) (SD) } \\
\hline In-hospital risk, $\%$ & $15.50(9.85)$ & $16.56(10.49)$ \\
\hline 6-month risk, \% & $25.30(12.73)$ & $27.50(15.00)$ \\
\hline \multicolumn{3}{|l|}{ Medications, $n(\%)$} \\
\hline Cholesterol reducers & $49(98)$ & $47(94)$ \\
\hline$\beta$-blockers* & $46(92)$ & $50(100)$ \\
\hline Platelet aggregation inhibitors & $48(96)$ & $48(96)$ \\
\hline Cardioaspirin & $47(94)$ & $48(96)$ \\
\hline Vasodilators & $36(72)$ & $35(70)$ \\
\hline Angiotensin-converting enzyme inhibitors & $31(62)$ & $35(70)$ \\
\hline Polyunsaturated fatty acids - omega- 3 & $11(22)$ & $10(20)$ \\
\hline Antihyperglycemics & $6(12)$ & $8(16)$ \\
\hline Diuretics & $6(12)$ & $5(10)$ \\
\hline Angiotensin receptor blockers & $5(10)$ & $4(8)$ \\
\hline Calcium antagonists* & $1(2)$ & $6(12)$ \\
\hline
\end{tabular}


Table 1 (continued)

\begin{tabular}{|c|c|c|}
\hline Variable & $\begin{array}{l}\text { CBT/WBT group } \\
(n=50)\end{array}$ & $\begin{array}{l}\text { CM group } \\
(n=50)\end{array}$ \\
\hline$\alpha$-adrenergic receptor inhibitors* & $0(0)$ & $4(8)$ \\
\hline Antihyperuricemics & $0(0)$ & $2(4)$ \\
\hline Antiarrhythmic & $1(2)$ & $0(0)$ \\
\hline Heart rate reducers & $0(0)$ & $1(2)$ \\
\hline 7 or more medications* & $11(22)$ & $23(46)$ \\
\hline \multicolumn{3}{|l|}{ Medical comorbidities, $n(\%)$} \\
\hline Digestive system diseases & $18(36)$ & $25(50)$ \\
\hline Endocrine diseases & $9(18)$ & $5(10)$ \\
\hline Circulatory/cardiac comorbidities & $2(4)$ & $4(8)$ \\
\hline Prostatic and male reproductive system diseases & $3(6)$ & $2(4)$ \\
\hline Urinary system diseases & $2(4)$ & $2(4)$ \\
\hline Orthopedic diseases & $1(2)$ & $3(6)$ \\
\hline Asthma & $3(6)$ & $1(2)$ \\
\hline Chronic obstructive pulmonary disease & $2(4)$ & $1(2)$ \\
\hline Stroke/aneurysm & $2(4)$ & $1(2)$ \\
\hline Heteroplasia/neoplasia & $2(4)$ & $1(2)$ \\
\hline Hyperuricemia & $0(0)$ & $3(6)$ \\
\hline Glaucoma & $1(2)$ & $0(0)$ \\
\hline Multiple sclerosis & $1(2)$ & $0(0)$ \\
\hline Cluster headache & $1(2)$ & $0(0)$ \\
\hline Cushing disease & $1(2)$ & $0(0)$ \\
\hline Sarcoidosis & $1(2)$ & $0(0)$ \\
\hline Thalassemia & $0(0)$ & $1(2)$ \\
\hline Rheumatoid arthritis & $0(0)$ & $1(2)$ \\
\hline 2 or more medical comorbidities & $12(24)$ & $13(26)$ \\
\hline \multicolumn{3}{|l|}{ Mean biomarkers (SD) } \\
\hline Hemoglobin, g/dL & $13.91(1.21)$ & $13.93(1.33)$ \\
\hline Platelets, $n \times 10^{3} / \mathrm{mm}^{3}$ & $235.42(57.64)$ & $232.96(50.20)$ \\
\hline Creatinine, $\mathrm{mg} / \mathrm{dL}$ & $0.94(1.78)$ & $0.95(0.20)$ \\
\hline Triglycerides, mg/dL & $115.96(52.91)$ & $121.69(58.68)$ \\
\hline HDL cholesterol, mg/dL & $51.98(16.59)$ & $46.51(12.01)$ \\
\hline LDL cholesterol, mg/dL & $87.40(25.48)$ & $93.96(29.25)$ \\
\hline Total cholesterol, mg/dL & $156.44(31.07)$ & $160.90(37.45)$ \\
\hline Glycated hemoglobin, $\mathrm{mmol} / \mathrm{mol}$ & $41.20(8.36)$ & $42.97(10.21)$ \\
\hline Fibrinogen, $\mathrm{mg} / \mathrm{dL}$ & $347.84(66.04)$ & $356.49(68.28)$ \\
\hline D-dimer, mg/L FEU & $0.68(1.39)$ & $0.45(0.39)$ \\
\hline $\mathrm{HRV}^{\mathrm{a}}, \mathrm{ms}$ & $51.10(27.66)$ & $41.50(12.29)$ \\
\hline \multicolumn{3}{|l|}{ C-reactive protein } \\
\hline $\mathrm{BO}, \mathrm{mg} / \mathrm{dL}$ & $0.19(0.21)$ & $0.39(0.69)$ \\
\hline $\mathrm{TO}, \mathrm{mg} / \mathrm{L}$ & $0.28(0.39)$ & $0.64(1.16)$ \\
\hline \multicolumn{3}{|l|}{ Mean SQ (SD) } \\
\hline Anxiety & $8.60(4.73)$ & $7.24(4.67)$ \\
\hline Depression & $7.92(4.77)$ & $6.90(4.87)$ \\
\hline Somatization & $9.82(5.65)$ & $7.82(5.12)$ \\
\hline Hostility & $4.70(4.00)$ & $5.34(4.36)$ \\
\hline \multicolumn{3}{|l|}{ Mean PWB (SD) } \\
\hline Autonomy & $62.20(9.18)$ & $61.80(9.25)$ \\
\hline Environmental mastery & $55.28(11.52)$ & $55.32(10.65)$ \\
\hline Personal growth* & $60.48(9.88)$ & $56.18(10.50)$ \\
\hline Positive relations with others & $61.26(13.26)$ & $60.20(10.68)$ \\
\hline Purpose in life & $56.80(11.51)$ & $56.22(11.59)$ \\
\hline Self-acceptance & $54.48(11.63)$ & $55.80(13.68)$ \\
\hline \multicolumn{3}{|l|}{ Mean CID-20 (SD) } \\
\hline CID-20 total score & $38.18(8.48)$ & $36.20(8.57)$ \\
\hline Depression (DSM), $n(\%)$ & $35(70)$ & $27(54)$ \\
\hline
\end{tabular}


Table 1 (continued)

\begin{tabular}{lcc}
\hline Variable & $\begin{array}{l}\text { CBT/WBT group } \\
(n=50)\end{array}$ & $\begin{array}{l}\text { CM group } \\
(n=50)\end{array}$ \\
\hline Major depression & $2(4)$ & $3(6)$ \\
Minor depression & $32(64)$ & $24(48)$ \\
Dysthymia & $1(2)$ & $0(0)$ \\
History of depression (DSM), $n(\%)$ & $34(68)$ & $26(52)$ \\
Demoralization (DCPR), $n(\%)$ & $47(94)$ & $44(88)$ \\
History of demoralization (DCPR), $n(\%)$ & $36(72)$ & $32(64)$ \\
Comorbidities, $n$ (\%) & $32(64)$ & $21(42)$ \\
$\quad$ Depression + demoralization* & & $19(38)$ \\
Chronicity of depression/demoralization, $n(\%)$ & $26(52)$ & $31(62)$ \\
$\quad$ Current + previous episode of depression & $35(70)$ & $(32)$ \\
$\quad$ Current + previous episode of demoralization & & \\
\hline
\end{tabular}

ACS, acute coronary syndrome; AMI, acute myocardial infarction; CBT, Cognitive-Behavioral Therapy; CID20, 20-item Clinical Interview for Depression; CM, clinical management; DCPR, diagnostic criteria for psychosomatic research; GRACE, Global Registry of Acute Coronary Events; HRV, heart rate variability; LVEF, left ventricular ejection fraction; NSTEMI, non-ST-segment elevation myocardial infarction; PTCA, percutaneous transluminal coronary angioplasty; PWB, Psychological Well-Being scales; SQ, Symptom Questionnaire; STEMI, ST-segment elevation myocardial infarction; WBT, Well-Being Therapy; BO, Bologna; TO, Torino. ${ }^{*} p \leq 0.05$. a Assessed only in Torino.

Fig. 2. CID-20 total scores at different time points (intention-to-treat analysis).

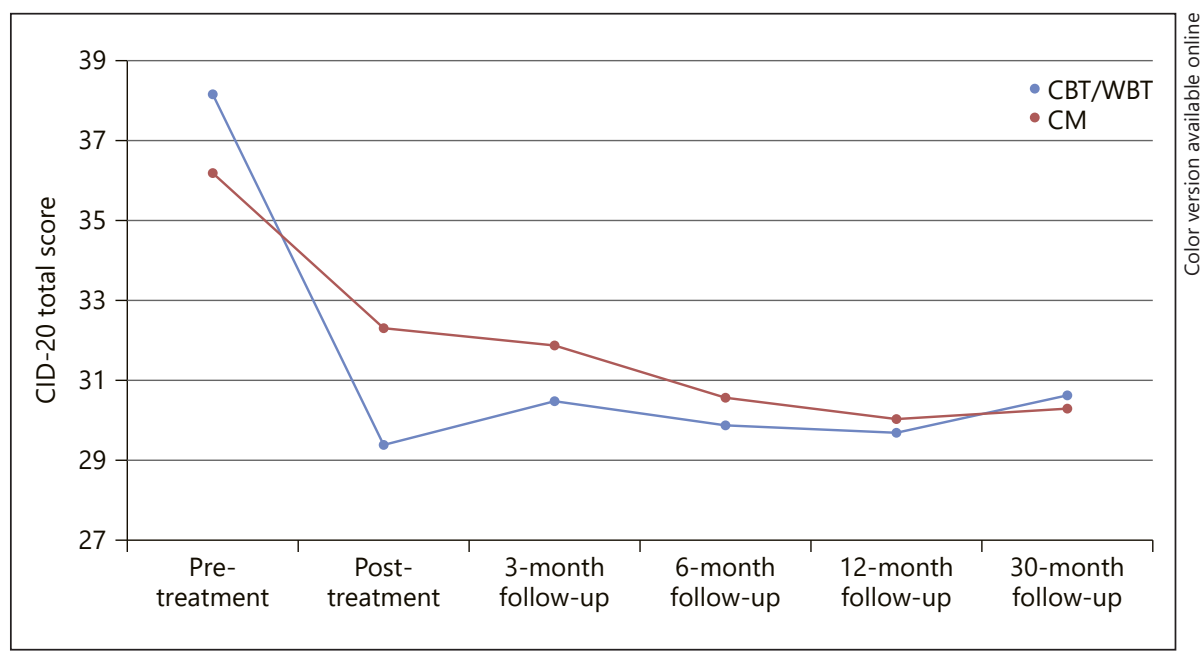

As for the CID-20 total score, a significant interaction between group allocation and time was found $(F=2.75$; $\mathrm{df}=3.85 ; p<0.05$; Fig. 2). Significant decreases in symptom scores from pre- to posttreatment were found in both the CBT/WBT $(p<0.001)$ and CM $(p<0.01)$ groups. However, the effect sizes for score modifications were strong in the CBT/WBT treatment group (Cohen's $d=$ 1.161 and 1.393 , respectively) and weak/medium among CM patients (Cohen's $d=0.492$ and 0.589 , respectively)
(Table 2). Patients allocated to CBT/WBT reported significant lower scores posttreatment $(p=0.040)$ compared to those assigned to CM. Starting from the 3-month follow-up, the CID-20 score differences between the 2 groups were no longer significant. The benefits, however, tended to persist in both groups.

No significant interactions were found between time and group allocation in relation to SQ and PWB mean scores, except for hostility as assessed by the SQ $(F=3.12$; 


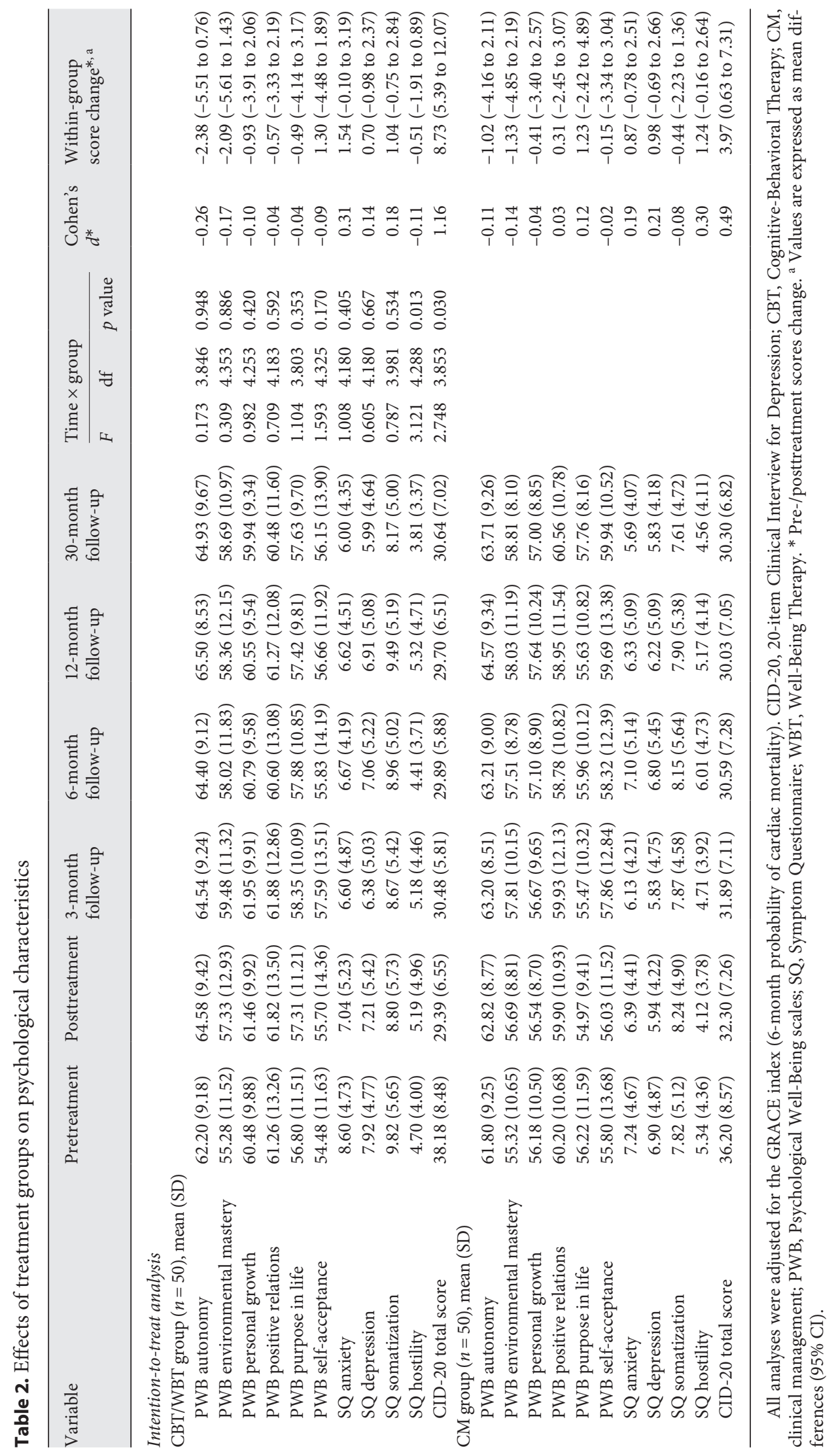




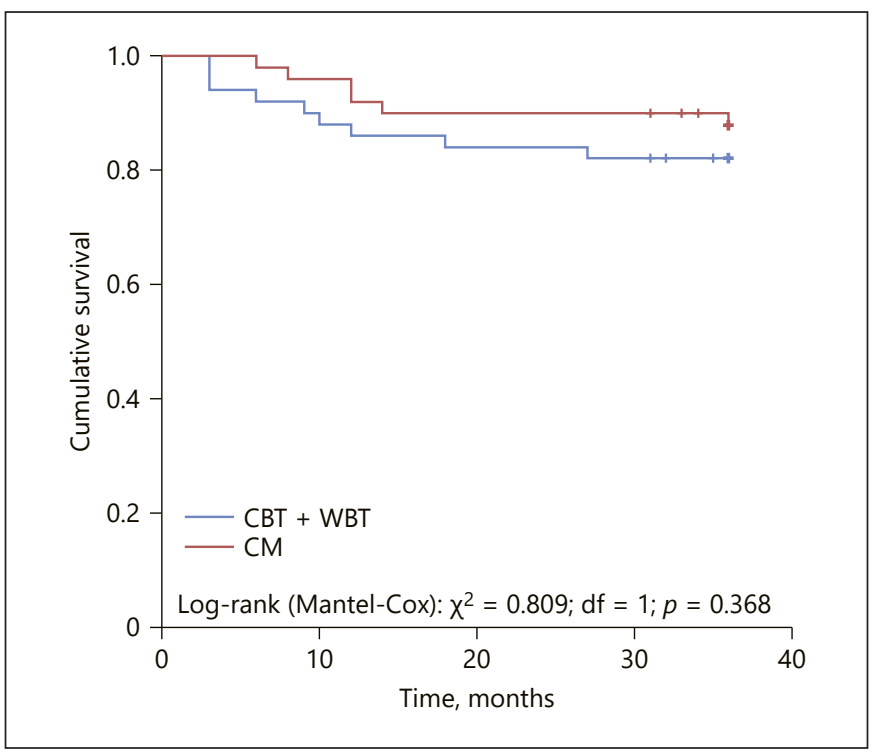

Fig. 3. Survival curves of the CBT/WBT and CM groups.

$\mathrm{df}=4.29 ; p<0.05$ ), with CM group showing significantly higher scores at the 6-month follow-up than CBT/WBT $(p=0.039$; Table 2).

\section{Biomarkers}

At the 3-month post-intervention follow-up, we observed a significant reduction of the frequencies of patients with biomarker levels considered to be at risk (below or above the median) only among patients allocated to the CBT/WBT group. In particular, we found a significant decrease in cases with a high platelet count (from 52 to $36 \% ; p<0.05$; median $=226 \times 10^{3} / \mathrm{mm}^{3}$ ), lower HDL cholesterol (from 52 to $34 \%$; $p<0.05$; median $=47 \mathrm{mg}$ / $\mathrm{dL}$ ), and a higher D-dimer level (from 56 to $40 \%$; $p<0.05$; median $=0.31 \mathrm{mg} / \mathrm{L} \mathrm{FEU}$ ) in patients assigned to CBT/ WBT compared to those receiving CM. No significant decrease in patients with risky levels of biomarkers was observed in the CM group.

\section{Survival Analyses}

Within 36 months from baseline, 15\% of the total sample had an adverse cardiac outcome. As for cardiac morbidity and mortality, we did not find any significant difference between the CBT/WBT and CM groups in terms of survival. Indeed, among the patients allocated to CBT/ WBT $16 \%(n=8)$ had nonfatal cardiac events and 1 patient (2\%) had a cardiac death (occurring after 18 months from baseline), whereas among the CM patients $10 \%$

Sequential Combination of CBT and

WBT in Depressed ACS Patients $(n=5)$ had nonfatal events and 1 patient $(2 \%)$ had a cardiac death (after 36 months from baseline). Nonetheless, the CBT/WBT patients displayed most of the negative cardiac outcomes within the first 9 months, with almost half of them (4 out of 9 ) relapsing during treatment sessions. On the contrary, CM participants were more likely to relapse after a longer period (starting after 8 months from baseline) (Fig. 3).

Stratifying the sample by group allocation, among CBT/WBT patients the probabilities of cardiac death, both in hospital (Wald $=4.235 ; \mathrm{df}=1 ; \mathrm{HR}=1.040 ; 95 \%$ CI 1.002-1.079; $p=0.040$ ) and at 6 months postdischarge (Wald = 4.594; $\mathrm{df}=1 ; \mathrm{HR}=1.031 ; 95 \%$ CI 1.003-1.060; $p=0.032)$ as calculated with GRACE indices, were found to predict a worse cardiac prognosis. On the contrary, in the CM group adverse cardiac outcomes were predicted by baseline scores of depression, as assessed by CID (Wald = 5.540; $\mathrm{df}=1 ; \mathrm{HR}=1.204 ; 95 \%$ CI 1.031-1.404; $p=0.019$ ).

\section{Discussion}

To our knowledge, this is the first RCT demonstrating a significant improvement in depressive symptoms and biomarkers in patients with ACS following sequential $\mathrm{CBT} / \mathrm{WBT}$ when compared with CM. This study provides new important clinical insights regarding the treatment of depression in the setting of ACS. The sequential combination of CBT/WBT was effective in significantly decreasing depressive symptoms compared to CM. In both groups the benefits persisted at follow-up, even though the differences between them faded (Fig. 2). It is noteworthy the different trend observed in the 2 groups concerning hostility, since it represents a key variable in the literature on the psychological issues embedded in depressive states [29] and it has been found to have a negative effect on the cardiac prognosis [30].

Medical outcomes did not differ between the 2 groups, yet among the CBT/WBT patients a negative cardiac prognosis was associated with a greater severity of the cardiac illness (as indicated by the GRACE indexes and the timing of relapses), whereas in the CM group it was associated with the severity of baseline depressive symptomatology. Moreover, patients who were assigned to the treatment group displayed significant decreases in placement according to normative values of platelet counts, HDL cholesterol, and D-dimer. There is evidence that these biomarkers may indicate a prognostic significance of the occurrence of cardiovascular events [31-33]. 
The findings are important in view of the methodology that was used. The patients were not assessed during hospitalization but rather after 1 month, when stress linked to hospitalization and the impact of acute illness are likely to subside and the evaluation of depressive symptoms is likely to be more reliable [34]. The impact of the CBT/WBT sequential combination was not compared to treatment as usual, as occurred in other studies [6], but rather to CM, where patients received the nonspecific elements of psychotherapy [27, 35]. Indeed, also CM yielded significant improvement in affective symptoms. This indicates that nonspecific support after ACS may be important, but specific psychotherapeutic strategies are associated with greater benefits and it underlines the need to schedule booster sessions (i.e., WBT or brief CBT) in order to reinforce progress or address potential obstacles to the continuance of the positive changes made during the therapy.

WBT is a short-term psychotherapeutic strategy that emphasizes self-observation of psychological well-being via the use of a structured diary, cognitive restructuring of interfering thoughts and/or behaviors, and homework assignments $[9,10]$. The working hypothesis was that lifestyle changes could only be achieved with a personalized approach that targets psychological well-being [9]. Based on examples taken from post-ACS everyday life, the patients allocated to CBT/WBT were instructed on how to overcome specific obstacles concerning lifestyle (i.e., specific strategies for medication adherence, scheduling of gradual physical exercises, and dietary modification according to specific prescriptions following hospital guidelines). In the phase that immediately follows ACS, interventions that bring the person out of negative functioning and distress may be important, and this was the target of the first phase of psychotherapy (CBT). However, facilitating progression toward restoration of the positive ("there is life after ACS") and appreciation of healthy lifestyle is another target that requires specific interventions (WBT). The results of this investigation confirm previous studies on the role of psychotherapeutic strategies in the setting of ACS [6] and provide a valid alternative/integration to pharmacological strategies, which carry the disadvantages of side effects of antidepressant drugs [36-37], with particular reference to cardiovascular safety [38]. The sequential psychotherapeutic strategy that was used may also be applied after pharmacological treatment of depression, if appropriate, and may have potential in extending therapeutic benefits beyond the time of medication administration, as it has been found to be the case in psychiatric settings [39].
This therapeutic approach may be potentially extended to cardiovascular rehabilitation in view of the suitability of WBT for the rehabilitation process [40] and the adverse prognostic role of an unhealthy lifestyle and depressive symptoms in these settings [41-43]. A number of clinical situations (delayed recovery after treatment, discrepancy between cardiovascular status/functioning, presence of a psychological comorbidity, problems with lifestyle and risky behavior, and presence of stressful circumstances) may be addressed by the sequential strategy we have outlined.

The findings of this investigation targeting psychological well-being in ACS should be seen as preliminary and await proper replication studies. It should also be noted that more than a quarter of the ACS patients diagnosed with depression and/or demoralization (36 out of 136; $26.5 \%)$ refused to join the RCT. This percentage, however, is lower than the refusal rates found in the literature on secondary prevention programs, which range from 31.4 [44] to $72.2 \%$ [45] among depressed patients. Moreover, about half of the 740 patients initially screened by the cardiologists refused to undergo psychological assessment and almost half of those who agreed refused to join the trial or revoked the initial consent. The results are thus likely to reflect a self-selected population. Nonetheless, they indicate a road to the practice of lifestyle medicine [46] that is worth perusing.

\section{Acknowledgement}

We thank all of the patients who agreed to be screened for the TREATED-ACS study and those who joined the trial. In addition, we thank Drs. Laura Alessi, Laura Staccini, Antonio Piolanti, Rachele Ceschin, Alessandra Munno, Emanuela Offidani, Corine Panepinto, Fedra Ottolini, Letizia Riva, and Daniela Calabrese, Mrs. Loretta Lollini, and all of the medical staff working at the Maggiore and Molinette hospitals for providing support.

\section{Statement of Ethics}

This study was approved by the institutional review board of the ethics committees of both centers (identifier: Studio CE 09058). Written informed consent was secured from all of the patients for both the initial psychological evaluation and trial participation, after the procedures had been fully explained to them. The participants did not receive any compensation. The authors assert that all of the procedures contributing to this work comply with the ethical standards of the relevant national and institutional committees on human experimentation and with the Helsinki Declaration of 1975, as revised in 2008 . 


\section{Conflict of Interest Statement}

The authors have no conflict of interests to declare.

\section{Funding Sources}

This work was supported by a grant from the Compagnia di San Paolo di Torino, Italy, to C.R.

\section{Author Contributions}

C.R., G.A.-D., and G.A.F. conceptualized and designed this study. C.R., S.G., G.A.-D., and G.A.F. collected, analyzed, and interpreted the data. C.R., S.G., and G.A.F. wrote the first draft of this paper. S.G. performed the statistical analyses. All of the authors critically revised this work for important intellectual content and provided administrative, technical, or material support. C.R., G.A.-D. and G.A.F. supervised the whole process.

\section{References}

1 Carney RM, Freedland KE. Depression and coronary heart disease. Nat Rev Cardiol. 2017 Mar;14(3):145-55.

2 Rafanelli C, Roncuzzi R, Milaneschi Y, Tomba E, Colistro MC, Pancaldi LG, et al. Stressful life events, depression and demoralization as risk factors for acute coronary heart disease. Psychother Psychosom. 2005 Apr;74(3):17984.

3 Kuhlmann SL, Arolt V, Haverkamp W, Martus P, Ströhle A, Waltenberger J, et al. Prevalence, 12-month prognosis, and clinical management need of depression in coronary heart disease patients. Psychother Psychosom. 2019 Sep;88(5):300-11.

4 de Figueiredo JM, Frank JD. Subjective incompetence, the clinical hallmark of demoralization. Compr Psychiatry. 1982 Jul-Aug; 23(4):353-63.

5 Kim JM, Stewart R, Lee YS, Lee HJ, Kim MC, Kim JW, et al. Effect of escitalopram vs placebo treatment for depression on long-term cardiac outcomes in patients with acute coronary syndrome: a randomized clinical trial. JAMA. 2018 Jul;320(4):350-8.

6 Reavell J, Hopkinson M, Clarkesmith D, Lane DA. Effectiveness of cognitive behavioral therapy for depression and anxiety in patients with cardiovascular disease: A systematic review and meta-analysis. Psychosom Med. 2018 Oct; 80(8):742-53.

7 Berkman LF, Blumenthal J, Burg M, Carney RM, Catellier D, Cowan MJ, et al.; Enhancing Recovery in Coronary Heart Disease Patients Investigators (ENRICHD). Effects of treating depression and low perceived social support on clinical events after myocardial infarction: the Enhancing Recovery in Coronary Heart Disease Patients (ENRICHD) Randomized Trial. JAMA. 2003 Jun;289(23):3106-16.

8 Kubzansky LD, Huffman JC, Boehm JK, Hernandez R, Kim ES, Koga HK, et al. Positive psychological well-being and cardiovascular disease: JACC health promotion series. J Am Coll Cardiol. 2018 Sep;72(12):1382-96.

9 Fava GA. Well-being therapy: Treatment manual and clinical applications. Basel, Switzerland: Karger Medical \& Scientific Publishers; 2016. https://doi.org/10.1159/isbn.978-3318-05822-2.
10 Guidi J, Rafanelli C, Fava GA. The clinical role of well-being therapy. Nord J Psychiatry. 2018 Aug;72(6):447-53.

11 Fava GA, Rafanelli C, Grandi S, Conti S, Belluardo P. Prevention of recurrent depression with cognitive behavioral therapy: preliminary findings. Arch Gen Psychiatry. 1998 Sep; 55(9):816-20.

12 American Psychiatric Association. Diagnostic and Statistical Manual of Mental Disorders. 4th ed., revised. Washington (DC): American Psychiatric Association; 2000.

13 Fava GA, Freyberger HJ, Bech P, Christodoulou G, Sensky T, Theorell T, et al. Diagnostic criteria for use in psychosomatic research. Psychother Psychosom. 1995;63(1):1-8.

14 Tang EW, Wong CK, Herbison P. Global Registry of Acute Coronary Events (GRACE) hospital discharge risk score accurately predicts long-term mortality post acute coronary syndrome. Am Heart J. 2007 Jan;153(1):2935.

15 First MB, Spitzer RL, Gibbon M, Williams J. Structured Clinical Interview for DSM-IVTR Axis I Disorders, research version. New York (NY): Biometrics Research, New York State Psychiatric Institute; 2002.

16 Porcelli P, Sonino N. Psychological factors affecting medical conditions: a new classification for DSM-V. Adv Psychosom Med. Basel: Karger; 2007.

17 Tecuta L, Tomba E, Grandi S, Fava GA. Demoralization: a systematic review on its clinical characterization. Psychol Med. 2015 Mar; 45(4):673-91.

18 Galeazzi GM, Ferrari S, Mackinnon A, Rigatelli M. Interrater reliability, prevalence, and relation to ICD-10 diagnoses of the Diagnostic Criteria for Psychosomatic Research in consultation-liaison psychiatry patients. Psychosomatics. 2004 Sep-Oct;45(5):386-93.

19 Paykel ES. The clinical interview for depression. Development, reliability and validity. J Affect Disord. 1985 Jul;9(1):85-96.

20 Guidi J, Fava GA, Bech P, Paykel E. The Clinical Interview for Depression: a comprehensive review of studies and clinimetric properties. Psychother Psychosom. 2011 Dec;80(1): $10-27$.
21 Hamilton M. Development of a rating scale for primary depressive illness. Br J Soc Clin Psychol. 1967 Dec;6(4):278-96.

22 Carrozzino D, Patierno C, Fava GA, Guidi J. The Hamilton Rating Scales for Depression: a critical review of clinimetric properties of different versions. Psychother Psychosom. 2020 May;89(3):133-50.

23 Kellner R. A symptom questionnaire. J Clin Psychiatry. 1987 Jul;48(7):268-74

24 Benasi G, Fava GA, Rafanelli C. Kellner's Symptom Questionnaire, a highly sensitive patient-reported outcome measure: systematic review of clinimetric properties. Psychother Psychosom. 2020 Mar;89(2):74-89.

25 Ryff CD. Happiness is everything, or is it? Explorations on the meaning of psychological well-being. J Pers Soc Psychol. 1989;57(6): 1069-81.

26 Ryff CD. Psychological well-being revisited: advances in the science and practice of eudaimonia. Psychother Psychosom. 2014 Dec; 83(1):10-28.

27 Guidi J, Brakemeier EL, Bockting CL, Cosci F, Cuijpers P, Jarrett RB, et al. Methodological recommendations for trials of psychological interventions. Psychother Psychosom. 2018 Sep;87(5):276-84.

28 Cohen J. Statistical power analysis for the behavioral sciences. New York (NY): Routledge Academic; 1988

29 Brummett BH, Babyak MA, Barefoot JC, Bosworth HB, Clapp-Channing NE, Siegler IC, et al. Social support and hostility as predictors of depressive symptoms in cardiac patients one month after hospitalization: a prospective study. Psychosom Med. 1998 Nov-Dec;60(6): $707-13$

30 Rafanelli C, Gostoli S, Tully PJ, Roncuzzi R. Hostility and the clinical course of outpatients with congestive heart failure. Psychol Health. 2016 Oct;31(2):228-38.

31 von Känel R. Acute mental stress and hemostasis: when physiology becomes vascular harm. Thromb Res. 2015 Feb;135(1):S52-5.

32 Vinholt PJ, Hvas AM, Frederiksen H, Bathum L, Jørgensen MK, Nybo M. Platelet count is associated with cardiovascular disease, cancer and mortality: a population-based cohort study. Thromb Res. 2016 Dec;148:136-42.
Sequential Combination of CBT and WBT in Depressed ACS Patients
Psychother Psychosom 2020;89:345-356 DOI: $10.1159 / 000510006$ 
33 Ishida M, Itoh T, Nakajima S, Ishikawa Y, Shimoda Y, Kimura T, et al. A low early highdensity lipoprotein cholesterol level is an independent predictor of in-hospital death in patients with acute coronary syndrome. Intern Med. 2019 Feb;58(3):337-43.

34 Fava GA, Sonino N. Depression associated with medical illness. CNS Drugs. 1996 Oct; 5(3):175-89.

35 Fava GA, Guidi J, Rafanelli C, Rickels K. The clinical inadequacy of the placebo model and the development of an alternative conceptual framework. Psychother Psychosom. 2017 Nov;86(6):332-40.

36 Carvalho AF, Sharma MS, Brunoni AR, Vieta E, Fava GA. The safety, tolerability and risks associated with the use of newer generation antidepressant drugs: a critical review of the literature. Psychother Psychosom. 2016; 85(5):270-88.

37 Fava GA, Rafanelli C. Iatrogenic factors in psychopathology. Psychother Psychosom. 2019 Jun;88(3):129-40.
38 Grace SL, Medina-Inojosa JR, Thomas RJ, Krause H, Vickers-Douglas KS, Palmer BA, et al. Antidepressant use by class: association with major adverse cardiac events in patients with coronary artery disease. Psychother Psychosom. 2018 Mar;87(2):85-94.

39 Guidi J, Tomba E, Fava GA. The sequential integration of pharmacotherapy and psychotherapy in the treatment of major depressive disorder: a meta-analysis of the sequential model and a critical review of the literature. Am J Psychiatry. 2016 Feb;173(2):128-37.

40 Nierenberg B, Mayersohn G, Serpa S, Holovatyk A, Smith E, Cooper S. Application of well-being therapy to people with disability and chronic illness. Rehabil Psychol. 2016 Feb;61(1):32-43.

41 Rafanelli C, Roncuzzi R, Finos L, Tossani E, Tomba E, Mangelli L, et al. Psychological assessment in cardiac rehabilitation. Psychother Psychosom. 2003 Nov-Dec;72(6):343-9.
42 Gostoli S, Roncuzzi R, Urbinati S, Morisky DE, Rafanelli C. Unhealthy behaviour modification, psychological distress, and 1-year survival in cardiac rehabilitation. Br J Health Psychol. 2016 Nov;21(4):894-916.

43 Gostoli S, Roncuzzi R, Urbinati S, Rafanelli C. Clinical and subclinical distress, quality of life and psychological well-being after cardiac rehabilitation. Appl Psychol Health Well-Being. 2017 Nov;9(3):349-69.

44 Turk-Adawi KI, Oldridge NB, Tarima SS, Stason WB, Shepard DS. Cardiac rehabilitation enrollment among referred patients: patient and organizational factors. J Cardiopulm Rehabil Prev. 2014 Mar-Apr;34(2):114-22.

45 Zullo MD, Gathright EC, Dolansky MA, Josephson RA, Cheruvu VK, Hughes JW. The influence of depression on utilization of cardiac rehabilitation post-myocardial infarction: a study of 158,991 Medicare beneficiaries. J Cardiopulm Rehabil Prev. 2017 Jan;37(1):22-9.

46 Rippe JM. Are we ready to practice lifestyle medicine? Am J Med. 2019 Jan;132(1):6-8. 